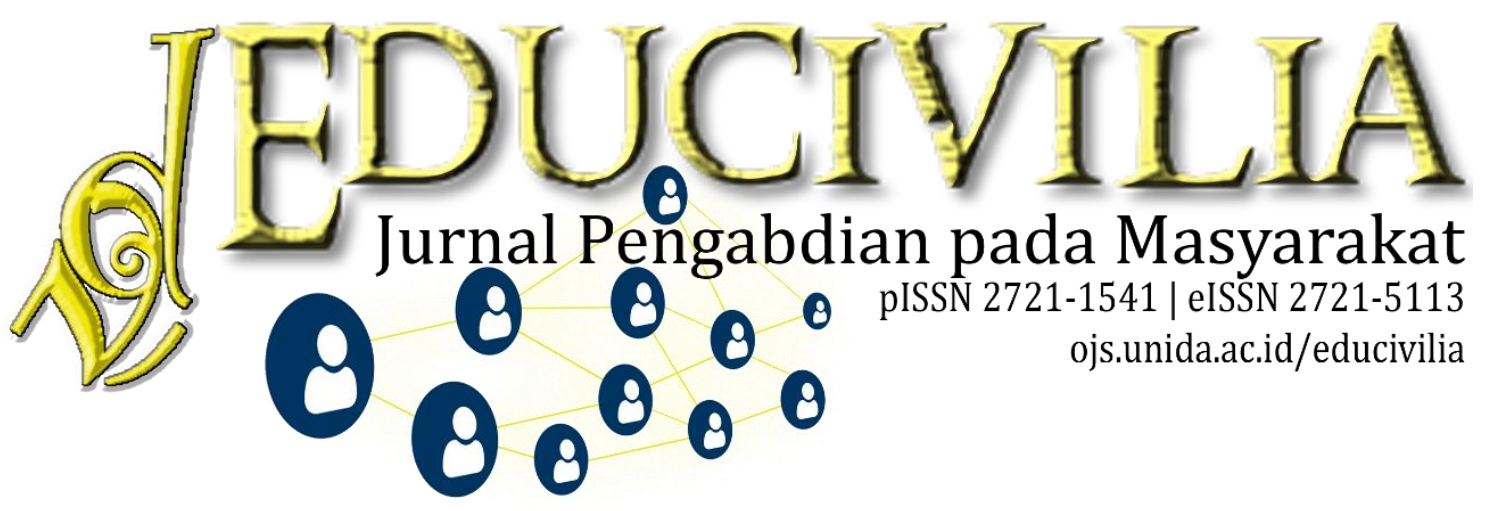

\title{
Rekam Kesehatan Personal Pada Anak Usia Sekolah Sebagai Kunci Sukses Pemberdayaan Kesehatan Siswa
}

\author{
Laela Indawati ${ }^{1}$, Nuryansyah Adijaya2 ${ }^{2}$, Deasy Rosmala Dewi ${ }^{3}$ Bayu Fajar Ilhami ${ }^{4}$ \\ 1,2,3,4Universitas Esa Unggul
}

Kilas Artikel
Volume 2 Nomor 1
Januari 2021: 73-81
DOI:
10.30997/ejpm.v2i1.3228
Article History
Submission: 09-09-2020
Revised: 14-11-2020
Accepted: 15-01-2021
Published: 27-01-2021
Kata Kunci:
Rekam Kesehatan Personal,
Rekam Medis, Rapor
Kesehatan, UKS
Keywords:
Personal Health Records,
Medical Records, Health
Report Cards, UKS
Korespondensi:
(Nuyansyah Adijaya)
(nuryansyah@esaunggul.ac.id)

\begin{abstract}
Abstrak
Anak usia sekolah merupakan sasaran strategis dalam pelaksanaan program kesehatan. Selain jumlahnya yang besar, yaitu (25\%) di antara jumlah penduduk, anak usia sekolah juga sasaran yang mudah dijangkau karena terorganisir dengan baik. Masalah kesehatan yang dialami anak usia sekolah sangat kompleks dan bervariasi. Permasalahan peserta didik di tingkat SD umumnya berhubungan dengan ketidakseimbangan gizi, kesehatan gigi, kelainan refraksi, kecacingan, dan penyakit menular yang terkait perilaku hidup bersih dan sehat. Program pengabdian kepada masyarakat masyarakat ini bertujuan untuk memberikan pengetahuan kepada guru dan orang tua murid terhadap buku rapor kesehatan atau rekam medis personal dan usaha kesehatan sekolah (UKS). Diharapkan dari kegiatan ini selain para guru dan orangtua dapat menambah wawasan, mengetahui tatacara pengisian buku rapor kesehatan sekolah dan program-program usaha kesehatan sekolah. Hasil akhir yang diharapkan adalah adanya peningkatan kesehatan dari para siswa/anak usia sekolah. Metode pendekatan yang digunakan untuk mencapai target luaran ditetapkan, yaitu pelatihan, bimbingan teknis, dan fasilitasi. Hasil pengabdian masyarakat ini adalah pemanfaatan kembali ruang UKS dan program kegiatan UKS beserta pemanfaatan buku rapor kesehatan sekolah untuk mencatat hasil pemeriksaan maupun riwayat sakit siswa.

\begin{tabular}{l}
\hline Personal Health Records in School-Age Children as the Key to \\
Successful Empowerment of Student Health \\
Abstract \\
\hline School age children are strategic targets in implementing health programs. \\
Apart from the large number, namely (25\%) of the total population, school \\
age children are also an easy target to reach because they are well \\
organized. The health problems experienced by school age children are very \\
complex and varied. The problems of students at the elementary level are \\
generally related to nutritional imbalances, dental health, refractive \\
errors, worms, and infectious diseases related to clean and healthy living \\
habits. This community service program aims to provide knowledge to \\
teachers and parents of students on health report books or personal medical \\
records and school health efforts (UKS). It is hoped that from this activity, \\
in addition to teachers and parents, they can add insight, know the \\
\hline
\end{tabular}
Successful Empowerment of Student Health

Abstract

School age children are strategic targets in implementing health programs. Apart from the large number, namely (25\%) of the total population, school organized. The health problems experienced by school age children are very complex and varied. The problems of students at the elementary level are generally related to nutritional imbalances, dental health, refractive errors, worms, and infectious diseases related to clean and healthy living habits. This community service program aims to provide knowledge to records and school health efforts (UKS). It is hoped that from this activity, in addition to teachers and parents, they can add insight, know the
\end{abstract}


procedures for filling out school health report books and school health business programs. The final expected result is an improvement in the health of students / school age children. The approach method used to achieve the output target is defined, namely training, technical guidance, and facilitation. The result of this community service is the reuse of the UKS room and the UKS activity program along with the use of school health report books to record the results of examinations and student illness history.

\section{PENDAHULUAN}

Anak usia sekolah merupakan sasaran strategis dalam pelaksanaan program kesehatan. Selain jumlahnya yang besar, yaitu (25\%) di antara jumlah penduduk, anak usia sekolah juga sasaran yang mudah dijangkau karena terorganisir dengan baik. Masalah kesehatan yang dialami anak usia sekolah sangat kompleks dan bervariasi. Permasalahan peserta didik di tingkat SD umumnya berhubungan dengan ketidakseimbangan gizi, kesehatan gigi, kelainan refraksi, kecacingan, dan penyakit menular yang terkait perilaku hidup bersih dan sehat. Pada peserta didik di tingkat lanjutan Sekolah Menengah Pertama (SMP), Madrasah Tsanawiyah (MTs), Sekolah Menengah Umum (SMU) dan Madrasah Aliyah (MA) SLB (Sekolah Luar Biasa) pada umumnya lebih banyak terkait dengan perilaku berisiko di antaranya kebiasaan merokok, mengkonsumsi minuman beralkohol dan melakukan hubungan seksual di luar nikah. Hasil riskesdas 2013 menunjukan bahwa prevalensi cedera pada anak usia 5-14 tahun sebesar $9,7 \%$ dan $11,7 \%$ pada anak usia 15-24 tahun, yang mayoritas disebabkan karena jatuh (40,9\%) dan transportasi motor (40,6\%). Data Global School Health Survey (GSHS) 2015 menunjukan bahwa anak usia sekolah 22,2 \% pernah merokok, 11,6\% saat ini masih merokok, 4,4\% pernah mengonsumsi alkohol, hal tersebut menunjukan adanya tantangan kesehatan yaitu meningkatnya kesenjangan dalam penerapan Perilaku Hidup Bersih dan Sehat (PHBS). Permasalahan kesehatan ini dapat diminimalisir melalui upaya promotif dan preventif kesehatan. [1]

Kementerian Kesehatan melalui program UKS telah melakukan upaya peningkatan kesehatan dalam bentuk promotif dan preventif. Upaya preventif antara lain kegiatan penjaringan kesehatan (skrining kesehatan) peserta 
didik [2]. Penjaringan kesehatan merupakan suatu prosedur pemeriksaan kesehatan yang dilakukan untuk memilah (skrining) anak yang sehat dan tidak sehat, serta dapat dimanfaatkan untuk pemetaan kesehatan peserta didik. Kegiatan ini dilaksanakan untuk memenuhi persyaratan Standar Pelayanan Minimal (SPM) bidang kesehatan dalam program Usaha Kesehatan Sekolah (UKS). Undang-Undang Kesehatan nomor 36 tahun 2009 pasal 79 menyebutkan bahwa kesehatan sekolah diselenggarakan untuk meningkatkan kemampuan hidup sehat peserta didik agar dapat belajar, tumbuh dan berkembang secara harmonis dan setinggi-tingginya menjadi sumber daya manusia yang berkualitas.

Tujuan dari penjaringan kesehatan adalah agar 1. Terdeteksinya secara dini masalah kesehatan peserta didik, sehingga bila terdapat masalah dapat segera ditindaklnajuti 2 . Tersedianya data atau informasi untuk menilai perkembangan kesehatan peserta didik, maupun untuk dijadikan pertimbangan dalam menyusun program pembinaan kesehatan sekolah. 3. Termanfaatkannya data untuk perencanaan, pelaksanaan, pemantauan dan evaluasi program pembinaan peserta didik.

Oleh karenanya kegiatan penjaringan kesehatan ini harus tercatat secara sistematis dan terstruktur agar riwayat kesehatan peserta didik dapat terdokumentasi dan datanya dapat dipakai untuk monitoring dan evaluasi program kesehatan, maupun untuk penggunaan pribadi peserta didik bila akan berobat ke pelayanan kesehatan. Pendokumentasian ini dapat dilakukan secara manual maupun elektronik. Pada tahun 2017 Kementerian Kesehatan melakukan uji coba dengan mengeluarkan buku rapor kesehatan bagi peserta didik sekolah dasar dan menengah dimana buku tersebut harus dibawa saat peserta didik mendapatkan pelayanan kesehatan di sekolah seperti penjaringan kesehatan, pemeriksaan berkala, pemberian tablet tambah darah, obat cacing, atau pada saat mendapat pelayanan kesehatan di puskesmas/fasilitas kesehatan lainnya. Peran tenaga kesehatan, guru/wali kelas adalah menjelaskan hasil pemeriksaan kepada peserta didik dan memantau pendampingan orang tua dalam menindaklanjuti saran dan rujukan. Sedangkan peran orang 
Rekam Kesehatan Personal Pada Anak Usia ...

tua/wali memantau status kesehatan peserta didik dan menandatangani hasil pemeriksaan kesehatan pada buku ini serta segera menindaklanjuti sesuai saran yang diberikan. [3]

Namun buku rapor kesehatan saat ini belum menjangkau semua sekolah, padahal banyak manfaat yang diperoleh dari buku rapor kesehatan. Sosialisasi dan pendistribusian buku rapor kesehatan baru dilakukan pada sekolahsekolah negeri, namun belum menyeluruh.

Yayasan Nurul Iman Pondok Bambu merupakan organisasi yang mengelola instansi pendidikan mulai dari Toodler, TK, SDI. Kendala yang ada saat ini adalah sudah adanya unit usaha kesehatan sekolah (UKS), namun belum dimanfaatkan dengan baik. Usaha Kesehatan Sekolah adalah usaha kesehatan masyarakat yang dijalankan di sekolah-sekolah dengan anak didik beserta lingkungan hidupnya sebagai sasaran utama. UKS merupakan wahana untuk meningkatkan kemampuan hidup sehat dan selanjutnya membentuk perilaku hidup sehat, yang pada gilirannya menghasilkan derajat kesehatan yang optimal. Untuk menerapkan buku rapor kesehatan di SD Islam Nurul iman, perlu diberdayakan kembali UKS sebagai wadah pelayanan kesehatan di sekolah. Undang-undang No. 23 tahun 1992 pasal 45 tentang kesehatan menyebutkan bahwa Usaha Kesehatan Sekolah wajib diselenggarakan di sekolah. Alasan Perlunya Usaha Kesehatan Sekolah adalah : (1) Anak usia sekolah merupakan kelompok umur yang rawan terhadap masalah kesehatan (2) Usia sekolah sangat peka untuk menanamkan pengertian dan kebiasaan hidup sehat (3) Sekolah merupakan institusi masyarakat yang terorganisasi dengan baik (4) Keadaan kesehatan anak sekolah akan sangat berpengaruh terhadap prestasi belajar yang dicapai (5) Anak sekolah merupakan kelompok terbesar dari kelompok usia anak-anak yang menerapkan wajib belajar (6) Pendidikan kesehatan melalui anakanak Sekolah sangat efektif untuk merubah perilaku dan kebiasaan ibu sehat umumnya.

Berdasarkan analisis situasi tersebut, maka tim pelaksana menggaris bawahi prioritas mitra yang dapat 
diselesaikan selama pelaksanaan pengabdian masyarakat. Permasalahan prioritas yang akan ditangani dalam program ini adalah :

a. Belum dimanfaatkannya UKS sebagai wadah untuk melakukan upaya pelayanan kesehatan di sekolah.

b. Belum adanya pemanfaatan buku rapor kesehatan sekolah / rekam kesehatan personal/rekam medis untuk mencatat hasil pemeriksaan kesehatan pada siswa sekolah

Untuk itu kami mencoba untuk melakukan pengabdian masyarakat pada sekolah swasta yaitu SD Islam Nurul Iman yang berlokasi di Pondok Bambu Jakarta Timur. Hal ini dilakukan sebagai upaya kami untuk mendukung program pemerintah khususnya Kementerian Kesehatan dengan memberdayakan kembali kegiatan Usaha Kesehatan Sekolah (UKS) dan pemanfaatan rekam kesehatan personal/buku rapor kesehatan.

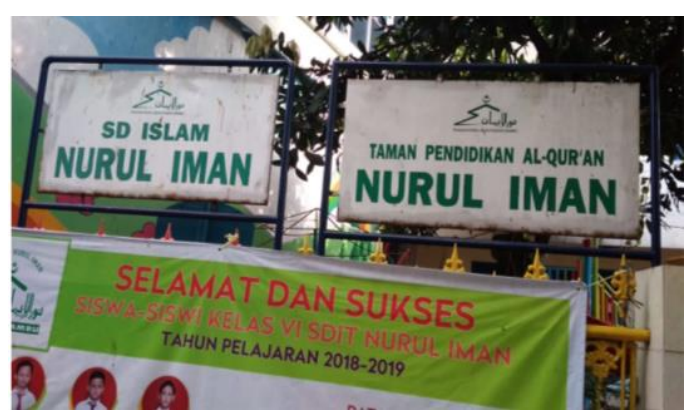

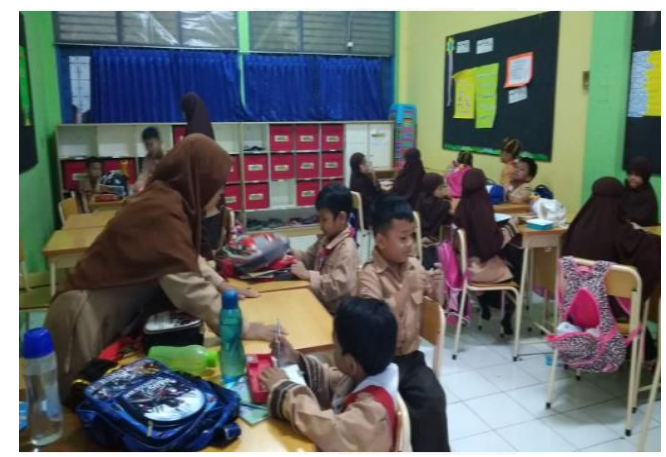

METODE

Berdasarkan solusi dan target luaran yang telah ditetapkan, maka tim menetapkan metode pendekatan sebagai berikut :

a. Metode Pelatihan

Metode pelatihan, ditujukan untuk mentransfer ilmu pengetahuan dan teknologi dalam mengatasi permasalahan melalui peningkatan wawasan, pemahaman bagi mitra. Pelaksanaan pelatihan direncanakan secara online melalui zoom. Metode ini ditetapkan oleh tim untuk mengatasi permasalahan, dan solusi mencapai target luaran yang telah ditetapkan.

b. Metode Bimbingan Teknis dan Pendampingan

Metode pendekatan ini ditujukan untuk mentranfer iptek agar mitra mampu mempraktekan hasil dari pendekatan pelatihan-pelatihan dengan bimbingan teknis dan pendampingan dari pakarnya, dimana metode 
pendekatan ini dilaksanakan langsung di lokasi mitra yaitu SD Islam Nurul Iman.

c. Metode Pendekatan Fasilitasi

Metode pendekatan ini ditujukan untuk mempermudah, meringankan, memperlancar, menghubungkan apa yang dibutuhkan oleh mitra. Pendekatan fasilitasi ini digunakan dalam mengatasi permasalahan dan mencapai target dan luaran.

\section{HASIL \& PEMBAHASAN}

\section{Sosialisasi}

Sosialisasi sekaligus rapat tim inti untuk persiapan kegiatan diadakan tanggal 22 Agustus 2020. Pihak mitra sangat antusias dan menyambut dengan baik rencana kegiatan Abdimas ini. Pada tahapan ini kami memberi penjelasan tentang rencana kerja abdimas yang akan dilaksanakan di lahan mitra, serta penjelasan singkat tentang buku rapor kesehatan sekolah. Pada kegiatan ini sekaligus dengan penyerahan buku rapor kesehatan sekolah yang terdiri dari buku informasi kesehatan, dan buku catatan kesehatan untuk dapat digunakan di lahan mitra.

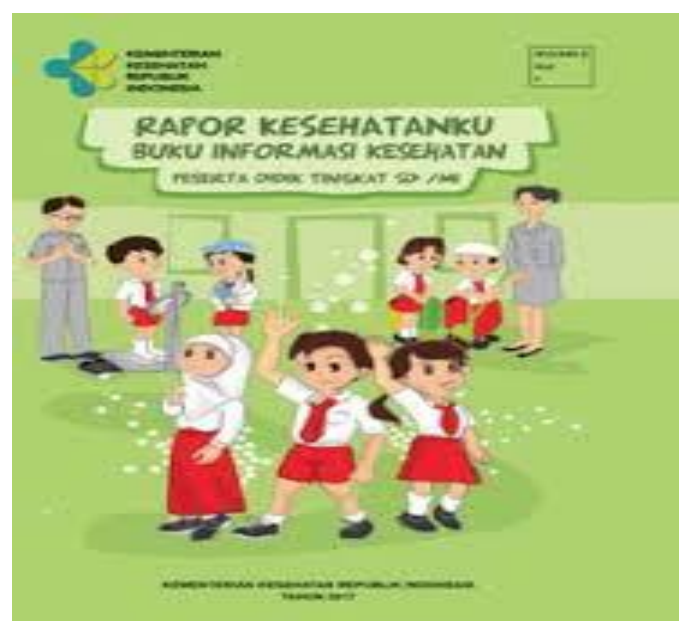

Gambar : Buku Informasi Kesehatan

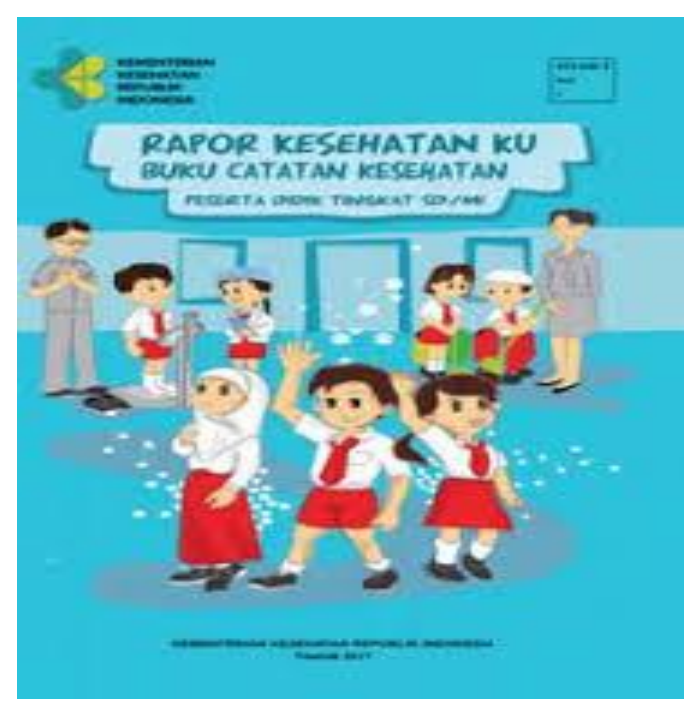

Gambar : Buku Catatan Kesehatan

2. Pelatihan

Sosialisasi dan Pelatihan kepada Guru-guru, orang tua siswa, dan siswa dilaksanakan pada hari Sabtu tanggal 29 Agustus 2020 yang dilaksanakan secara daring/virtual.

Pada sosialisasi dan pelatihan ini dijelaskan tentang pentingnya buku rekam kesehatan sekolah, dan tatacara penggunaan serta pengisian buku rekam kesehatan sekolah dimana dalam 
penggunaan dan pengisian buku ini akan melibatkan guru, orang tua murid, dan siswa, dengan tanggungjawabnya masing-masing.

Pihak Mitra sangat membantu dan berkontribusi dalam kegiatan ini dengan memfasilitasi pembuatan surat undangan kegiatan yang ditujukan ke orangtua murid, dan media yang kami gunakan untuk sosialisasi dan pelatihan.
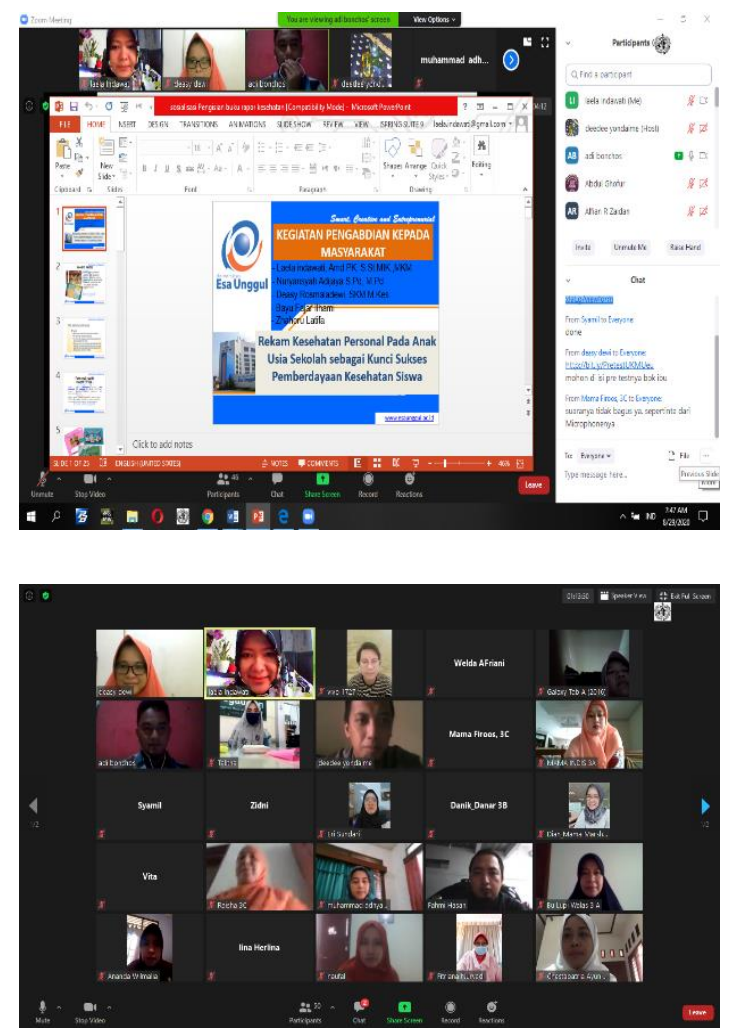

Gambar. Kegiatan sosialisasi dan pelatihan

Metode Bimbingan teknis dan pendampingan yang awalnya direncanakan, belum dilaksakanan dengan optimal karena dalam kondisi pandemi, sekolah belum melakukan kegiatan belajar tatap muka. Sehingga pelaksanaan pengisian dan kegiatan UKS belum dapat dijalankan. Untuk itu kegiatan kami fokuskan dengan metode pendekatan fasilitasi.

\section{Fasilitasi}

Kami berupaya untuk memfasilitasi ruang UKS dengan menyediakan perlengkapan yang dapat digunakan bila sekolah sudah melakukan kegiatan tatap muka, dengan menyediakan tempat tidur periksa, tempat cuci tangan portabel, thermometer, alat pengukur tinggi badan, alat pengukur berat badan, dan kotak P3K beserta obat-obatannya. Dengan adanya fasilitas perlengkapan yang kami berikan, diharapkan dapat membantu mitra, khususnya peserta didik agar mendapatkan fasilitas yang nyaman terkait kesehatannya, dan program kegiatan UKS dapat terlaksana dengan baik.

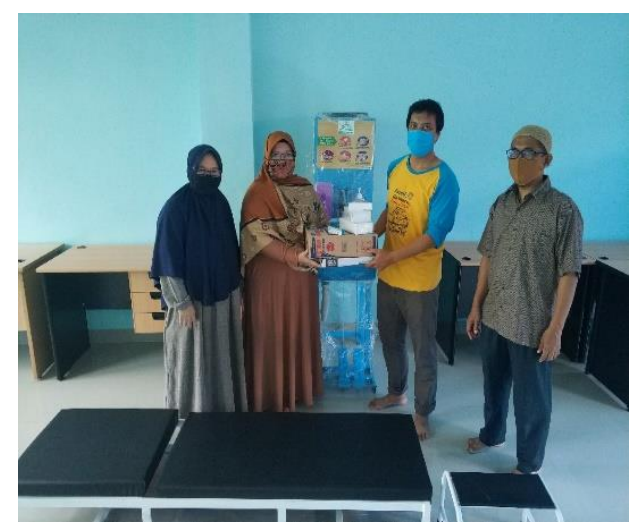

Gambar. Serah terima perlengkapan UKS 
Rekam Kesehatan Personal Pada Anak Usia ...

McGonigle dan Mastrian (2011) menyatakan ada delapan komponen penting yang membantu keselamatan pasien dalam pelayanan perawatan kesehatan yaitu 1. informasi kesehatan dan data; 2. manajemen hasil; 3. petunjuk manajemen pamasukan data; 4. dukungan keputusan; 5. komunikasi elektronik dan konektivitas; 6. dukungan pasien; 7. proses administrasi; 8. laporan dan manajemen populasi kesehatan. Berkaitan dengan sistem informasi, salah satunya terdapat Clinical System Information (CIS) seperti Electronic Health Records (EHR) atau Rekam Kesehatan Elektronik (RKE) dan Electronic Personal Health Records (EPHR). [5]

Rekam Kesehatan Personal belum di implementasikan di Indonesia, namun beberapa Negara maju sudah menerapkan rekam kesehatan personal ini. Di negara maju perkembangan rekam kesehatan elektronik mengalami peningkatan seperti di New York yang sudah mengembangkan rekam perawatan maternitas elektronik (electronic maternity care records) [6]. Sedangkan di Zambia, Sub-Saharan
Afrika telah melaksanakan perawatan prenatal dan melahirkan secara komprehensif dengan model pencatatan yang disebut Zambia Electronic Perinatal Records System (ZEPRS) dari tahun 2007- 2010 [7]. Pemanfaatan RME di Australia yang diteliti oleh Homer, et.all, 2010 dengan pemanfaatan Personal Digital Assistant (PDA) sebagai alat interactive antenatal electronic maternity record melalui sistem ObyMate [9], dan akhir tahun 2010 Australia mengembangkan lagi rekam kesehatan khusus di area maternitas yaitu Mater Shared Electronic Record (Rekam Elektronik Kesehatan Maternitas Bersama) untuk pasien maternitas dan bayi baru lahir sebagai pengembangan aplikasi PCEHR (Personally Controlled Electronic Health Record) [9].

Dengan pemanfaatan buku rapor kesehatan sekolah, yang merupakan rekam kesehatan personal khusus anak usia sekolah, menjadi langkah awal untuk meningkatkan kesehatan pada masyarakat, khususnya pada anak usia sekolah, dimana riwayat kesehatan anak dapat terpantau dengan baik. 


\section{SIMPULAN}

Pihak sekolah perlu melaksanakan program-program UKS secara optimal agar peserta didik dapat terbiasa hidup sehat dan memahami pentingnya kesehatan. Media untuk mendokumentasikan riwayat kesehatannya juga perlu ada. Dengan adanya buku rapor kesehatan sekolah ini, guru, orang tua siswa, dan peserta didik dapat memaksimalkan penggunaannya untuk mencatat hasil kegiatan penjaringan kesehatan, maupun riwayat kesehatan siswa, dan mendapatkan edukasi dari buku informasi kesehatan, yang menjadi bagian dari buku rapor kesehatan.

\section{UCAPAN TERIMA KASIH}

Ucapan terima kasih kami sampaikan kepada Direktorat Riset dan Pengabdian Masyarakat (DRPM), Direktorat Jenderal Penguatan Riset dan Pengembangan KEMENRISTEK DIKTI atas pendanaan Hibah Pengabdian Kepada Masyarakat tahun 2019, Ketua Yayasan Nurul Iman, Kepala Sekolah SDIT Nurul Iman dan jajarannya serta para pendidik, para siswa, orang tua/wali siswa, serta semua pihak yang turut menyukseskan dan membantu kegiatan pengabdian masyarakat ini.

\section{DAFTAR PUSTAKA}

http:/ / www.depkes.go.id/resources/ download/general/Hasil\%20Riske sdas \%202013.pdf

Peraturan bersama 4 Menteri No. 6/X/PB/2014, Nomor 73 tahun 2014, nomor 41 tahun 2014, Nomor 81 tahun 2014 Tentang Pembinaan dan Pengembangan Usaha Kesehatan Sekolah

http:/ / kesga.kemkes.go.id/images/pe doman/Rapor \%20Catatan \%20Kese hatan \%20SD

\%20MI_MJC_Rev_OKE.pdf

https://en.wikipedia.org/wiki/Person al_health_record

McGonigle, Dee dan Mastrian, Kathleen. (2011). Nursing Informatics and the Foundation of Knowledge 2 nd edition. Canada: Ascend Learning Company

Chilbirth Connection Organisation. (2011). Transforming Maternity Care Blueprint for Action Development and Use of Health Information Technology

Benjamin, et. all. (Januari, 2011). Implementation of the Zambia Electronic Perinatal Record System for comprehensive prenatal and delivery care. International Journal of Gynecology and Obstetrics 113, hal. 131-136

Homer, et al. (Juni, 2010). Developing an interactive electronic maternity records. British Journal of Midwifery,Vol 18, No 6, hal.384-389. Strachan, Michael. (April, 2011). Mater Shared Electronic Health Record for Maternity and Newborn Patients 